\title{
Making electronics more accessible to people with learning disabilities
}

Conference or Workshop Item

Published Version

Hollinworth, N., Hwang, F., Allen, K., Kwiatkowska, G. and Minnion, A. (2014) Making electronics more accessible to people with learning disabilities. In: Human Factors in Computing Systems (CHI '14), 26 Apr - 1 May 2014, Toronto, Canada. Available at http://centaur.reading.ac.uk/36529/

It is advisable to refer to the publisher's version if you intend to cite from the work. See Guidance on citing.

Published version at: http://dx.doi.org/10.1145/2559206.2581175

All outputs in CentAUR are protected by Intellectual Property Rights law, including copyright law. Copyright and IPR is retained by the creators or other copyright holders. Terms and conditions for use of this material are defined in the End User Agreement. 


\section{CentAUR}

Central Archive at the University of Reading

Reading's research outputs online 


\section{Making Electronics More Accessible to People with Learning Disabilities}

\section{Nic Hollinworth}

School of Systems Engineering

University of Reading

Whiteknights, Reading

RG6 6AY

n.d.hollinworth@reading.ac.uk

\section{Faustina Hwang}

School of Systems Engineering

University of Reading

Whiteknights, Reading

RG6 6AY

f.hwang@reading.ac.uk

\section{Kate Allen}

Department of Art

University of Reading

1 Earley Gate,

Whiteknights Road

Reading RG6 6AT

k.allen@reading.ac.uk

Permission to make digital or hard copies of part or all of this work for personal or classroom use is granted without fee provided that copies are not made or distributed for profit or commercial advantage and that copies bear this notice and the full citation on the first page. Copyrights for third-party components of this work must be honored. For all other uses, contact the Owner/Author. Copyright is held by the owner/author(s)

CHI 2014, April 26 - May 1, 2014, Toronto, ON, Canada.

ACM $978-1-4503-2474-8 / 14 / 04$

http://dx.doi.org/10.1145/2559206.2581175

\begin{abstract}
We extended 'littleBits' electronic components by attaching them to a larger base that was designed to help make them easier to pick up and handle, and easier to assemble into circuits for people with learning disabilities. A pilot study with a group of students with learning disabilities was very positive. There were fewer difficulties in assembling the components into circuits, and problems such as attempting to connect them the wrong way round or the wrong way up were eliminated completely.
\end{abstract}

\section{Author Keywords}

Learning disabilities; sensory objects; accessibility; electronics

\section{ACM Classification Keywords}

H.5.m. Information interfaces and presentation (e.g. $\mathrm{HCI}$ ): Miscellaneous.

\section{Introduction}

Electronic kits are now widely available [e.g. 4, 8, 10], and designed to encourage experimentation and promote understanding of technology. Many kits feature snap-together components that support the rapid assembly of simple circuits, and require little or no knowledge of electronics to create working systems. This was the motivation for introducing the littleBits kit 
[2] into a series of workshops we organised for a group of people with learning disabilities.

The workshops are an integral part of an interdisciplinary project - Interactive Sensory Objects for and by People with Learning Disabilities - that engages a group of people with learning disabilities as co-researchers [e.g. 1, 3] in art-based and technology focused activities that explores how we can create interactive multisensory objects that could help to enhance exhibits at museums or heritage sites, making a visit more interesting, meaningful and fun. The littleBits kits were used to explore how the different senses could augment existing artefacts or create entirely new ones. For example, different methods of triggering audio were explored, such as clapping, using a bend sensor and using a squeeze sensor.

Despite the potential of using the simple electronic components, there were a number of practical issues in using littleBits, specifically related to people with learning disabilities, which we wanted to address to make the components more accessible to our coresearchers. This paper outlines the work in progress of our extended littleBits components, and how they can help to overcome some of the challenges in using them with people with learning disabilities.

\section{Background}

The co-researchers in our workshops are all in their early 20s, two male and five female, and enrolled at Reading College on the LLD/D (Learning Difficulties and/or Disabilities) course. Varying degrees of communication difficulties are evident and generally low levels of literacy and numeracy. They have a broad spectrum of learning disabilities and associated physiological impairments such as Sotos syndrome, Fragile X, Down's syndrome and various forms of autism.

The co-researchers all have difficulties with either fine motor control, coordination, or ability to pick up objects, which can affect their ability to use technology. Physical difficulties such as clumsiness and gross motor impairment are common in individuals with Asperger's or high functioning autism, and processing

abnormalities of auditory or tactile sensory information in autism is high [5]. Lack of fine motor control is associated with Sotos syndrome (cerebral gigantism) [11] and difficulties with processing sensory information and coordinating movements [4], motor difficulties such as clumsiness, slowness of movement [7] and impairments with fine motor skills (e.g. threading beads, cutting with scissors) are common in individuals with Down's syndrome [12].

The focus of technological developments for people with learning disabilities has been largely through enabling mechanisms that provide access to ICT, such as textto-speech engines, organisational software [6] or technology to assist with physical impairments. There has been little consideration given to helping to promote understanding of, and the use of, the wide variety of technologies currently available, including electronics kits. It was an aim of our workshops to find methods to enable our co-researchers to experiment with technology for themselves.

\section{Exploring the Senses with littleBits}

During the workshop sessions, the co-researchers explored their senses through art-based activities, and looked at ways in which the senses could be engaged 
through the development of sensory objects that could help to improve cultural understanding and experiences. The littleBits kits contain small electronic components that snap together to make circuits, and were used as a vehicle for exploring the potential of technology. The co-researchers were encouraged to experiment with different methods of using and triggering media using littleBits, which could eventually be integrated into their own artwork.

To get started with using the littleBits components, three basic circuits, each comprising a power source, trigger and output, were provided on printed worksheets (see Figure 1 for an example), closely matching the physical layout of the components. The assembly of the littleBits components could then be compared with the worksheet to see if they matched the illustration on paper (see Figure 2).

EXAMPLE 1 : PUSH BUTTON AND LED
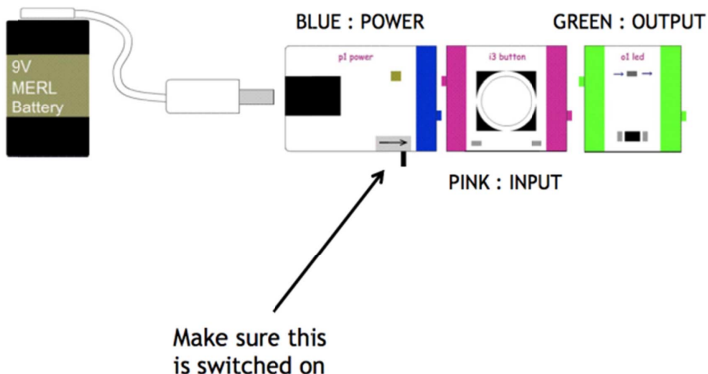

Figure 1: littleBits worksheet that describes how to construct a simple circuit containing a power source, button and LED.
Although the co-researchers were very enthusiastic about using the components (often wanting to continue the activities past the scheduled time), and responded positively to their introduction, most needed help in physically assembling them into working circuits.

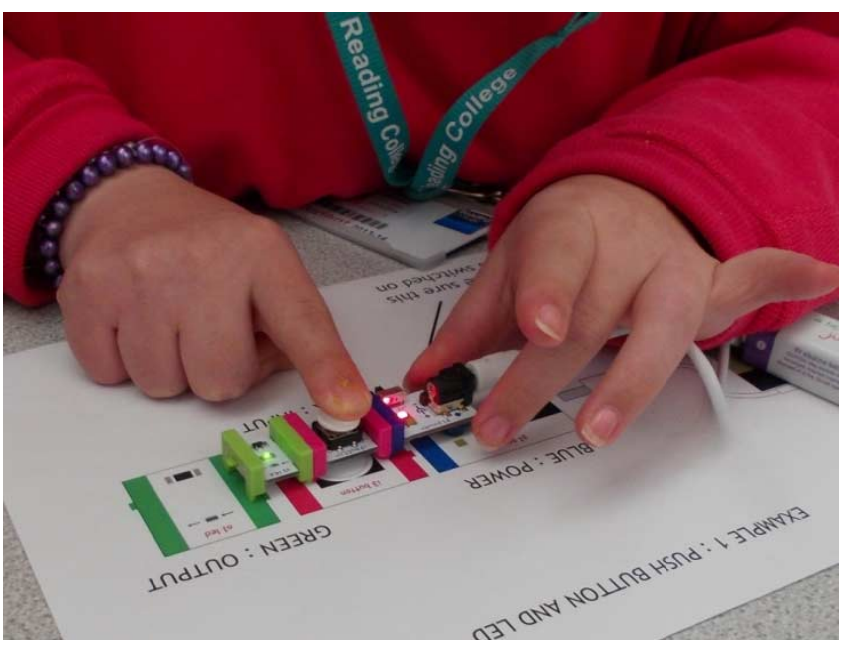

Figure 2: This circuit was constructed by one of the coresearchers, but required some assistance from support staff.

\section{Challenges with Simple Electronics}

We observed a number of challenges associated with the practical use of the littleBits kit in the workshop sessions:

1. The littleBits components snap together via pairs of magnets on each face. Most of the bits have two faces, the input side and the output side, but it is difficult to tell which side is for which. If it is the wrong way round, then the magnets repel, and the objects will not snap together. This occurred quite frequently. 


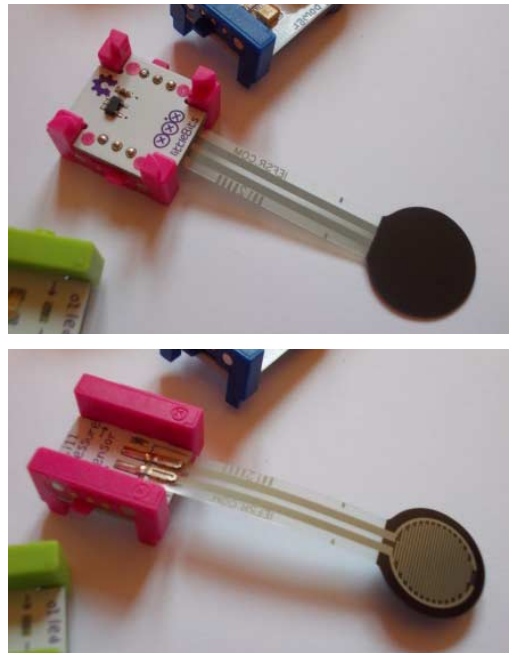

Figure 3: A force sensor. Top image: upside down. Bottom image: the right way up.

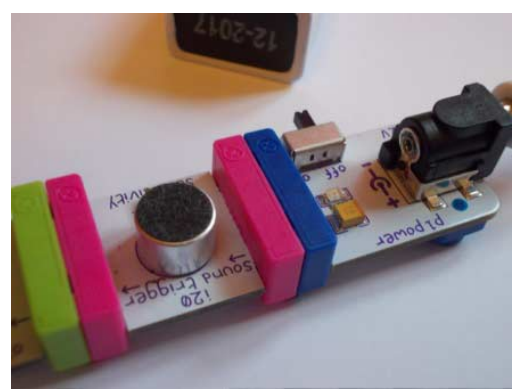

Figure 4: The sound trigger (a microphone) resembles a small button, which caused many people to press it, instead of making a sound such as a clap.
2. It can be difficult to tell whether the component is the right way up, as the top and bottom are similar in appearance. If the component is upside down, then you cannot connect the bits together. This also occurred quite frequently (see Figure 3 in sidebar, left).

3. The affordances of the bits are often unclear, so it is not always obvious what they are intended to do or how to use them. For example, the sound trigger has a small condenser microphone on top, which resembles a small button. This caused many people to press it, rather than talk into it or clap their hands near to it, as it is intended to be used (see Figure 4 in sidebar, bottom left).

4. Whilst not a criticism of the design, the components are small, making them difficult to grasp, which can be a problem for our coresearchers many of whom have limited motor control or manual dexterity, and may cope better with handling objects which are larger.

5. The components themselves were difficult to handle, but the controls on the littleBits objects were even more difficult. Figure 5 shows two of the co-researchers together adjusting the potentiometer on a 'pulse' component (a timed trigger). This needs to be turned using a small screwdriver with a slot size measuring about $2 \mathrm{~mm}$. Although the two group members shown here managed to adjust the tiny controls, this was with some difficulty and it was clear that they could benefit from larger, more robust, controls.

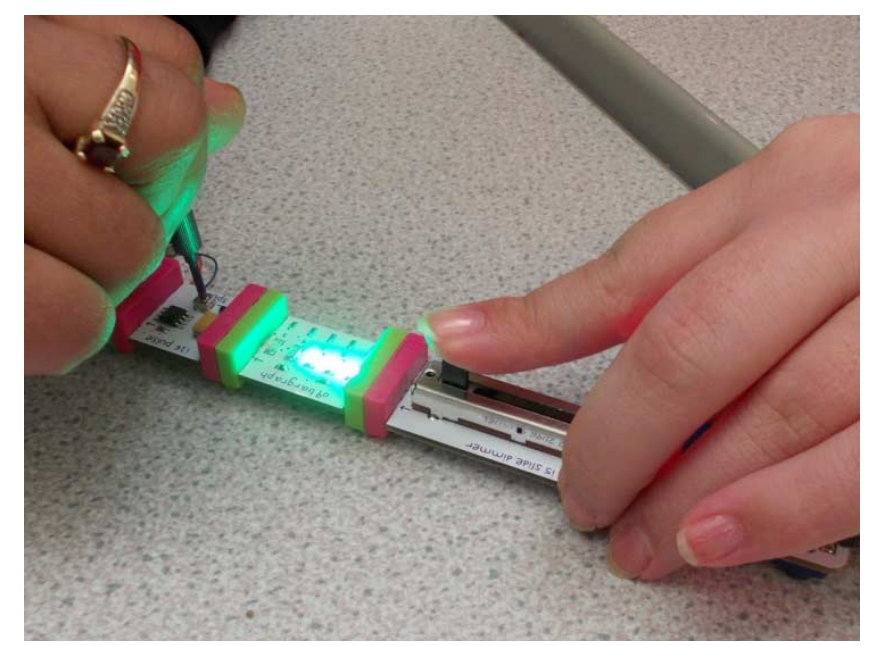

Figure 5: Two of the group members exploring a bargraph, slider control and pulse. Adjusting the pulse speed was quite difficult for them using the small controls.

\section{LittleBits Go Larger}

To help improve the usability of littleBits for our coresearchers, we developed a 'base' with which to attach the existing littleBits components (see Figure 6 in sidebar), allowing us to employ their functionality but using a larger format. The base is asymmetrical so that the front of one base slots into the rear of another, preventing the components from being connected the wrong way round and this addresses challenge 1 above. The design also ensures that the components are the right way up by having only one side which is flat, addressing challenge 2. above. Being physically much larger than the existing littleBits components, the base provides a larger surface area for grasping, which may aid people with limited manual dexterity, addressing 4. above (see Figure 7). 

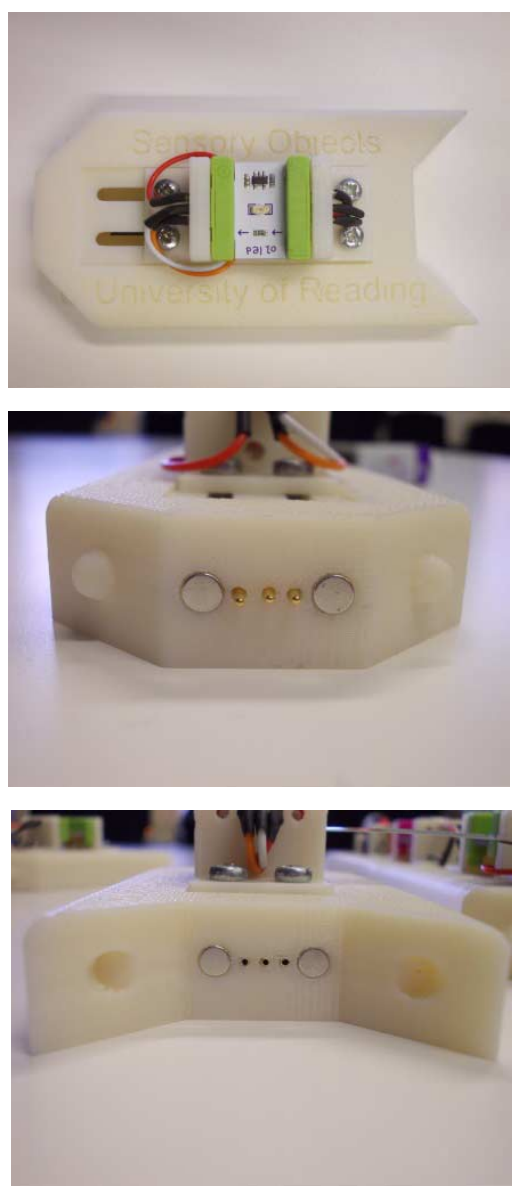

Figure 6: Extended base for littleBits. Top image show extended LED, middle image shows front view and bottom image show rear

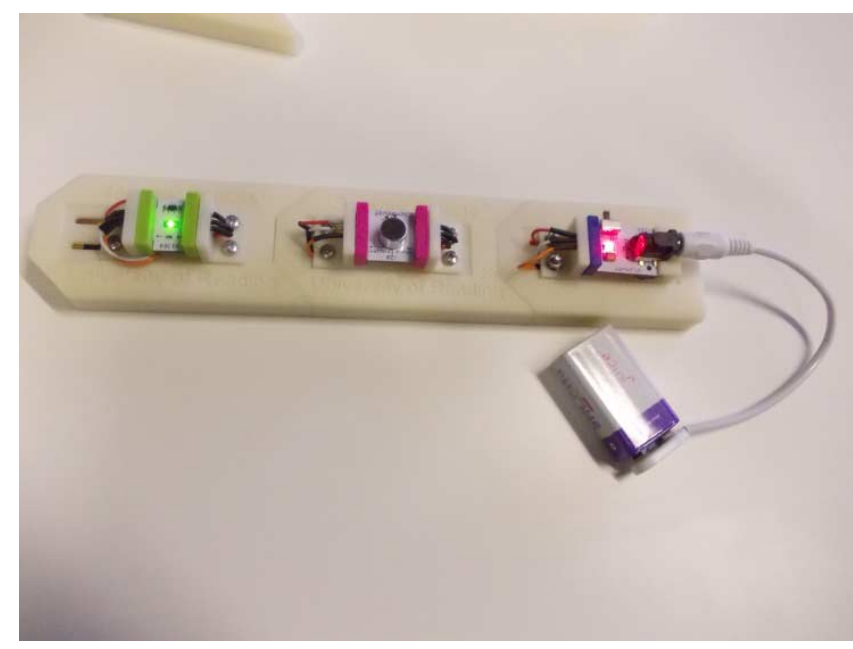

Figure 7: Top view of enlarged base for littleBits components, showing an LED control mounted on the base.

The large base does not deal with the problem of adjusting small controls, nor affordances and so does not offer any improvements in adjusting the small controls, understanding how to assemble the components into circuits, or how the components are used and what they are intended to do. A major challenge is to redesign the components in such a way as to make the order of assembly, and their purpose, clear. This could make them more usable, but at the cost of being less flexible.

\section{Pilot Test}

The littleBits base was piloted with six of the coresearchers. Each was given two output devices (a vibration motor and an LED), two input devices (a sound trigger and squeeze sensor) and a power supply. They were then instructed to assemble the components into simple circuits, each circuit using the power supply, one input and one output device. The aim was to see if the new format would help with issues 1,2 and 4 above, rather than on understanding the components.

For each circuit, the co-researchers were told which parts to use, but not how to assemble them or in what order. If they placed the components in the wrong order, then they were instructed to swap the order of the components and then check that the circuit works correctly. At the end of the session, each co-researcher was asked, using a talking mats technique [e.g. 9], if they found using the larger components easy or difficult, and whether they liked or disliked using them.

\section{Results and Discussion}

All six co-researchers indicated that they found the exercise easy and all six indicated that they enjoyed using them. Comparison of observations made in previous workshop sessions using the standard littleBits components indicated that handling of the larger components was clearly easier (see Figure 8 in sidebar), as less assistance was required during assembly into circuits. The problem with getting the components the right way up and the right way round showed a clear improvement, as there were no difficulties with slotting the components together (see Figure 9 in sidebar).

The potential benefits of making electronic kits accessible to people with learning difficulties are to encourage creativity and experimentation (using kits which are 'safe' and cannot get damaged with experimenting), increase awareness of technology, improve reasoning skills through assembling working circuits, and help to communicate ideas with respect to the use of technology, particularly within the context of creating interactive objects. 


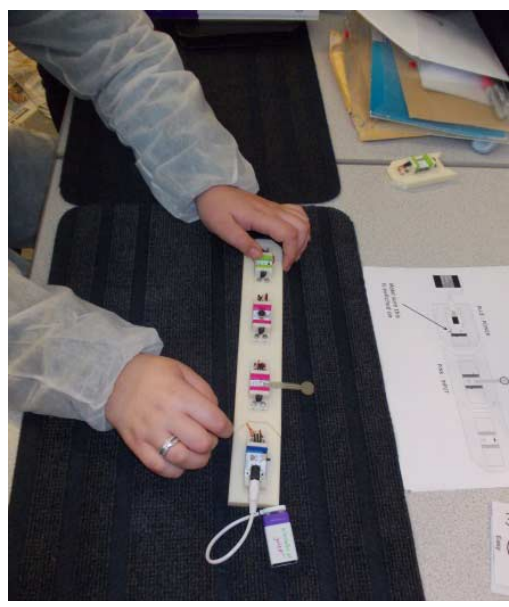

Figure 8: One of the co-researchers assembling a circuit.

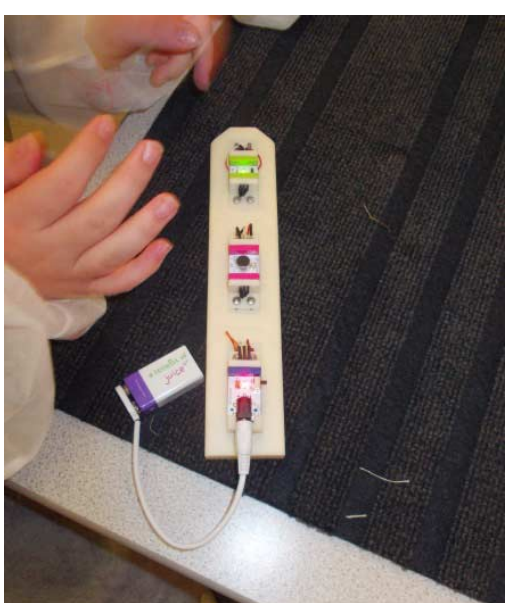

Figure 9: One of the co-researchers having assembled a circuit, tries out the sound trigger to activate an LED.
For future work, although the issues noted in 1,2 and 4 above were improved, there still remain at least two challenges:

1. components are often connected in the wrong order e.g. connecting a power supply to an LED component, and then adding a button at the end so the circuit either would not work at all or would not work as intended.

2. The purpose of components and how they are supposed to be used is often misunderstood, so clearer affordances are needed. This would necessitate a redesign of some components.

The next phase of the study will address the first of these challenges with the development of larger controls that do not require external tools (such as a screwdriver), and a lower level of fine motor control.

\section{Acknowledgements}

The research is funded by the Arts and Humanities Research Council (AHRC), grant AH/J004987/1. We thank Reading College and The Museum Of English Rural Life at the University of Reading. Thanks also to Andrea Alessandrini for making us aware of littleBits. littleBits is a trademark of littleBits inc.

\section{References}

[1] Anthony, L., Prasad, S., Hurst, A., \& Kuber, R. A. Participatory design workshop on accessible apps and games with students with learning differences. In Proceedings of the 14th international ACM SIGACCESS conference on Computers and accessibility, 2012, 253-254, ACM.

[2] Bdeir, A. Electronics as material: littleBits. In Proceedings of the 3rd International Conference on
Tangible and Embedded Interaction (TEI '09). ACM, New York, NY, USA, 2009, 397-400

[3] Benton, L., Johnson, H., Ashwin, E., Brosnan, M., \& Grawemeyer, B. Developing IDEAS: Supporting children with autism within a participatory design team. In Proceedings of the SIGCHI conference on Human factors in computing systems, 2012, 25992608, ACM.

[4] http://www.brightminds.co.uk/electronic-kits/c12, last accessed on 23/12/2013

[5] Dawson, $\mathrm{G}$ and Watling, R. Interventions to Facilitate Auditory, Visual, and Motor Integration in Autism: A Review of the Evidence. Journal of Autism and Developmental Disorders, 2000, 30, 415-421

[6] Forgrave, K. Assistive Technology: Empowering Students with Learning Disabilities. The Clearing House, 2002, 75, 3, 122-126

[7] Frith, $U$ and Frith C.D. Specific Motor Disabilities in Down's Syndrome. Journal of Child Psychology and Psychiatry, 1974, 5, 293-301

[8] http://littlebits.cc/ Last accessed on 23/12/2013

[9] Murphy, J. and Cameron, L. The effectiveness of Talking Mats with people with intellectual disability British Journal of Learning Disabilities. Blackwell Publishing Ltd, 2008, 36, 232-241

[10] http://www.cambridgebrainbox.co.uk/PrimaryPlus2.html, last accessed on 23/12/2013

[11] Sotos, J. and Cutler, E. Cerebral Gigantism. American Journal Dis Child, 1977, 131, 625-626

[12] Spano, M., Mercuri, E., Rando, T., Panto, T., Gagliano, A., Henderson, S. and Guzzetta, F. Motor and perceptual-motor competence in children with Down syndrome: variation in performance with age. European Journal of Paediatric Neurology, $1999,3,7-14$ 